\title{
Sewage Work and Occupational Health Hazards: An Anthropological Insight
}

\author{
Ajeet Jaiswal* \\ Department of Anthropology, Pondicherry University, India \\ *Corresponding author: Ajeet Jaiswal, Assistant Professors, Department of Anthropology, Pondicherry University, Puducherry, India

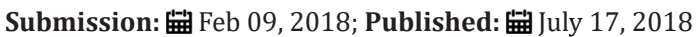

\begin{abstract}
Occupational health has gradually developed from a mono-disciplinary, risk- oriented activity to a multi-disciplinary and comprehensive approach that considers an individual's physical, mental and social well-being, general health and personal development. The present article aimed at highlighting the anthropological insight on the occupational health hazards among the Sewage works of India. Nodoubt Occupational health aimed at the protection and promotion of the health of workers by preventing and controlling occupational diseases and accidents and by eliminating occupational factors and conditions hazardous to health and safety at work but still apart from the social atrocities, these sewage workers are also exposed to many occupational health hazards like exposure to harmful gases, drowning, musculo skeletal disorders, infections, skin problems, respiratory system problem and cardiovascular degeneration.

Present article also discuss about management of toxic Gases that came from sewages and have direct effect on the health of the sewage workers like Hydrogen sulfide, Carbon Monoxide (CO) Gas, Ammonia Gas, Carbon Dioxide, Methane Gas and also represent the important safety measures and safety guide for men working in sewers like Safety is first, statutory provisions for safety, safety equipment, breathing apparatus, air house respirator portable lighting equipment, non sparking Tools, portable air blowers, safety belt, inhalators, and diver's suit along with this article also tries to explain about selection of sewer workers, Training and Prerequisite
\end{abstract}

Keywords: Health; Occupation; Hazards; Sewage worker; Toxic gases; Safety

\section{Introduction}

Occupational health is a multidisciplinary activity aimed at the protection and promotion of the health of workers by preventing and controlling occupational diseases and accidents and by eliminating occupational factors and conditions hazardous to health and safety at work. it also aimed the development and promotion of healthy and safe work, work environments and work organizations; the enhancement of the physical, mental and social well-being of workers and support for the development and maintenance of their working capacity, as well as professional and social development at work; enabling workers to conduct socially and economically productive lives and to contribute positively to sustainable development [1].

Occupational health has gradually developed from a monodisciplinary, risk- oriented activity to a multi-disciplinary and comprehensive approach that considers an individual's physical, mental and social well-being, general health and personal development [2]. Apart from the social atrocities sewage workers face, they are also exposed to many occupational health hazards. These health hazards can be categorized under following heads:
A. Exposure to harmful gases
B. Drowning
C. Musculo skeletal disorders
D. Infections
E. Skin problems
F. Respiratory system problem
G. Cardiovascular degeneration

\section{Exposure to harmful gases}

The worker are commonly exposed to gases like hydrogen disulphide, methane, carbon dioxide Ammonia, carbon monoxide, and the level of oxygen can be below what is required to breathe. Workers are aware that these gases may be present but there are no reliable means of testing

From moderate exposure (500 to $700 \mathrm{ppm}$ ) there is a loss of consciousness lasting a few minutes, but no respiratory difficulty. 
In cases of sever poisoning the subject drops into a profound coma with dyspnoea, polypnoea and a slate blue cyanosis until breathing restarts; there are tachycardia and tonic-clinic spasms.

Inhalation of massive quantities of hydrogen sulphide will rapidly produce anoxia resulting in death by asphyxia; epileptic form convulsions may occur and the individual falls apparently unconscious, and may die without moving again. This is a syndrome characteristic of hydrogen sulphide poisoning in sewer workers; however in such cases exposure is often due to a mixture of gases including methane, nitrogen, carbon dioxide and ammonia. In subacute poisoning, gases affect the eyes with palpebral edema, bulbar conjunctivitis, mucopurulent secretion and a reduction in visual acuity. This syndrome is known to sugar and sewer workers as "Gas eye" [3].

\section{Drowning}

Death due to drowning is not common, but excess water in sewer lines is dangerous.

\section{Musculo-skeletal disorders}

Osteo arthritic changes and intervertebral disc herniation are the common spinal abnormalities reported in these workers, Friendrich et al. [4] Studied 255 sewage works to determine the prevalence of spinal troubles (i.e., neck, upper back and low back pain). He reported that the 12 month prevalence rates of neck, upper back and low back pain were $52.4 \%, 45.8 \%$ and $72.8 \%$ respectively. The prevalence of spinal trouble increased with age work disability during the preceding 12 months due to LBP was significantly positively associated with age, disability. The weekly duration of topping and lifting 5 years previously and higher abnormal illnessbehaviour scores (odds ratio between 1.26 and 0.94)[4].

\section{Infections}

The modes of exposure for the various infections are as follows:

a. The most common way is by hand to mouth contact during eating. Drinking and smoking, or by wiping the face with contaminated hands or gloves or by licking splashes from the skin.

b. By skin contacts through cuts, scratches, or penetrating wounds I.e from discarded hypodermic needles harmful organisms can enter the body through the surface of the eyes, nose and month

c. By breathing them in as dust aerosol or mist.

The infections commonly studied among this group of workers include Leptospirosis Hepatitis and Helicobacter pylori, typhoid, and worm infections.

\section{Leptospirosis}

Leptospirosis is an important occupational disease affecting people coming in contact with animals and their discharges. The occurrence of infection in one's workplaces is linked to the environment to which the works is exposed and the adaptability of the organism in that working environment. Rodents usually live in underground sewers and are carriers of leptospira. The urine of rodents and other animals present in that area is likely to contaminate these sewers, Letptospira are excreted in the urine of infected animals. Thus sewer workers are at a potential risk of leptospirosis. Ambedkar et al. [2], studied 78 sewer workers from 5 different municipal wards in Pune to find out the evidence of past infection with leptospira using Micro-Agglutination Test (MAT). The prevalence rate was found to be $16.6 \%$. Evidence of leptospiral infection was found to be maximum in sewer workers in the areas of the city that were infested with rodents and stray animals. De Serres et al. [5], found that sewer workers has a greater prevalence of antibodies against leptospirosis than controls $(12 \% \mathrm{v} 2 \%$, $\mathrm{p}=0.003$ )

\section{Hepatitis}

Hepetitis 'A' virus (HAV) is the most frequently occurring, preventable disease. Although generally self limiting, acute hepatitis A is associated with substantial morbidity and related economic burden. Few studies reported increased HAV antibodies among sewage workers while other studies suggest that though worker in solid waste industry may be only theoretically at increased risk of acquiring infectious diseases occupationally. Even a systematic review carried out by Glas et al. [6], does not confirm an increased risk of clinical HA in workers exposed to sewage. Vaidya et al. [7] reported a significant rise in ant-HEV Positivity $(\mathrm{p}<0.05)$ was recorded in sewage worker working more years. Another case report suggests that sewer workers may be at increased risk of contracting hepatitis C. Another study by Arvanitidou et al. [8], among employees of a sewage company, only exposure to sewage was independently associated with positive for HBV infection $(p<0.001)$. The recommended that works exposed to sewage should therefore be considered for vaccination against hepatitis B Virus.

\section{Helicobacter pylori}

An increased risk for gastric cancer among sewage workers has been described in several studies. During the last decade the bacterium Helicobacter pylori has emerged as one important risk factor for gastric cancer and is now considered a class I carcinogen by the international Agency for research on cancer. Friis et al. [9], studied the prevalence of immunoglobulin G (IgG) antibodies against $\mathrm{H}$ Pylori in a group of 289 municipal workers. The prevalence of IgG antibodies against $\mathrm{H}$ Pylori among sewage workers did not differ from that of the referents. However the increase in the prevalence of $\lg G$ antibodies against $\mathrm{H}$ Pylori with increasing age was observed. Several other infections like intestinal parasitic infections, gastroenteritis, and pontaic fever are found among the sewage workers.

\section{Skin problems}

Chemicals present in the sewerage affect the skin, high level of acidity and alkalinity causes burns, redness, sores, eczema, and irritation.

\section{Respiratory symptoms and function}

Several studies have been carried out to study the respiratory function of sewage workers and all reported that respiratory infections are common among these groups of workers and all 
reported that respiratory infections are common among these groups of workers. These symptoms may be due to exposure to end toxins and airborne bacteria by way of bio aerosols. Zuskin et al. [10], reported that the baseline ventilator capacity was significantly decreased compared to predict values in sewage workers in particulars, values for FEF 25-50 were reduce suggesting obstructive changes in smaller airways. They mentioned that sewage workers are exposed to different occupational noxious agent which may lead to the development of chronic lung function changes.

\section{Management of Toxic Gases of Sewage Worker's}

There are many toxic gases that came from sewages and have direct effect on the health of the sewage workers like Hydrogen sulfide, Carbon Monoxide (CO) Gas, Ammonia Gas, Carbon Dioxide, and Methane Gas.

\section{Hydrogen sulfide (H2S) gas (rotten egg gas; sewer gas; stink damp)}

Hydrogen sulfide is an extremely toxic; choking gas its toxicity is similar to Hydrogen Cyanide or Hydrocyanic acid (HCN). H2S Poisoning is one of the leading causes of sudden death due to toxic gases. Hydrogen sulfide occurs naturally in crude petroleum, natural gas, volcanic gases and hot springs and also present as a byproduct in different industries like Sewage treatment plant, Coke oven, Paper mills, Tanneries, Petroleum refineries, Dyes, Leather, Processing of sugar, Manufacture of Nuclear Reactor. Even bacterial decomposition of organic matter containing preparations leads to the formation of many toxic gases likes' hydrogen sulfur, carbon dioxide, ammonia and methane.

Hydrogen sulfide causes local irritation and inflammation of the tissues and exposed mucus membranes of eyes and respiratory tract. On contact with water it forms caustic sulphides. It inhibits respiratory enzyme cytochrome oxidase by binding with iron. This leads to decrease in oxidative phosphorylation resulting in depression of cellular respiration. Hydrogen sulfide affects the Eye, Respiratory tract and Cardio vascular system of human being

Fire and explosion: Mixtures of H2S and air in the explosive may explode violently. When exposed to heat it decomposes to hydrogen and sulfur. In contact with oxidizing agents it may react violently and ignite spontaneously. Extinguishing agents include carbon dioxide, chemical dry powder and water sprays [11].

Health effects: Low Level exposure produces effects on Eye, Headache and Asthenia. High Level concentration produces Cardio vascular problem like myocardial depression, respiratory system problem like dyspnoea, cough, chest pain, pulmonary edema, hypoxia etc and even nervous disorder may also possible in case of high concentration exposure.

Treatment of acute poisoning: Treatment must be prompt with immediate removal of the victim from the poisonous environment. Airway protection and ventilator support must be ensured with $100 \%$ oxygen or oxygen mixed with $5-7 \%$ carbon dioxide. Amyl nitrate inhalation is to be started at once by breaking the ampoules on a handkerchief and holding it near the nose of the patient. Inhalation should be for 30 seconds every minute until intravenous access is established [5].

Work place monitoring: This is usually done with different detectors specific for detecting $\mathrm{H} 2 \mathrm{~S}$ gas. They include Fixed monitoring system like sensors with alarm, Personal Electronic monitors, Lead acetate coated strips (strip turn black due to the formation of black colored sulfides), Tube detectors (it is used for short term measurement). When H2S concentration is more than $70 \mathrm{mg} / \mathrm{m} 3$, evacuation of the place is immediately ordered.

Hazard control like engineering control (control at source by having a proper enclosed system of the entire plant process), Administrative control (providing proper training to the personnel). In addition to this, general awareness can be enhanced by putting various safety posters, display boards and providing different safety equipments like (personal protectors) at specified areas etc. its success depends much upon having an efficient disaster management plan. Periodic medical examination should be done every six months. Health records are to be maintained in specified health registers.

\section{Carbon Monoxide (CO) gas}

$\mathrm{CO}$ is the most toxic substance, you will contact in daily life at home, at work, in industry, garage, car, boat etc. Worldwide, emission 232 million tons per year (USA 88 million tons per year).CO is produced by the incomplete combustion of carbon or carbonious material i.e. gas, oil, coal or wood or illuminating gas and exhaust fumes. $\mathrm{CO}$ also produced from boilers, engines, motor vehicles, gas furnaces, gas lines, water heaters, coke ovens and catalytic radiant heaters, Smoke from cigarettes, stoves, burning houses and gas arising from explosions. $\mathrm{CO}$ combines with $\mathrm{Hb}$ to from carboxyHb. $\mathrm{CO} \mathrm{Hb}$ is incapable of carrying oxygen so tissue anoxia results. Also combines with my globing of muscles and interferes with cytochrome oxidase system.

CO is called as "The Silent Killer". It occur naturally in our body, $0.5 \% \mathrm{COHb}$ present produced by normal metabolism. Smoker taking a pack of cigarettes per day achieves $5 \% \mathrm{COHb}$. A garage worker achieves $3-15 \% \mathrm{COHb}$ at the end of day. A worker after 8 hours of job at 50ppm exposure achieves $8-10 \%$ COHb. $20 \%$ $\mathrm{COHb}$ produces distinct symptoms of toxicity. $65 \% \mathrm{COHb}$ is fatal. When the exposure of $\mathrm{CO}$ is more than 1 hours and concentration is more than 500ppm than exposure of CO causes headache, Nausea, greater activity irritability, increased chest pain, confusion, and if the concentration of $\mathrm{CO}$ is more than $1000 \mathrm{ppm}$ than a condition of unconscious and even respiratory failure or death may arise. Prolonged Exposure in 100-200ppm for $13 \mathrm{hr}$ with serve physical stress causes persistent headache, Physical \& mental Asthenia, Giddiness, Persistent insomnia, Insomnia, Impaired Memory, Mask like Face and Parkinsonism Symptoms etc.

Risk management: All combustion devices must be vented outside. Air concentration of $\mathrm{CO}$ to be kept below exposure limit 
by proper ventilation. Periodical checkup of CO gas Sensitive Zone by detector. Gas cleaning operations to be done with precautions. Maintain $\mathrm{CO}$ concentration maximums at 50ppm for 8 hours working period. In case of Leakage, reduce furnace load below 15MW. Switch of CO fan and CO compressor and close pneumatic valve. Do not operate Electrical switches. Cordon off and evacuate the isolated spot [6].

Treatment: Remove the victim immediately to fresh air. Administer artificial respiration. Give $100 \% 02$ by mask (3-5lit/ min.). 02 containing 5-7\%CO2by nasal tube. 20\% mannitol (1gm/ $\mathrm{kg}$ ) intravenous over $20 \mathrm{~min}$ to reduce cerebral oedema. Cooling Blankets for reducing hyperthermia. Anti-biototics for bacterial aspiration pneumonia. Bed rest for 2-4 weeks to minimize late neurological complications. Complete recovery is not likely if symptoms of mental detoration persist / for $>2$ weeks.

\section{Ammonia gas}

Ammonia gas is an Irritant Asphyxiates, colourless gas with pungent suffocation odour. Found in or as Occupational exposure, Agricultural fertilizers, Metal furnaces, Laboratories, Furnaces, Fertilizers manufacturing unit, Refrigerant, Chemical industry, Explosive manufacturing, Coke making unit [12].Exposure of Ammonia gas produces health hazards like Conjunctivitis, Ulceration of cornea, Skin burns, Blindness, Pulmonary edema, Pain in the mouth and throat, Keratitis, Blood stained sputum, Corneal Opacities, Ulceration of the mucosa, Action depends on solubility, Ammonia dissolves in upper respiratory tract so effect on lung may not be seen. Tolerance- adaptation occurs in workers [7].

Treatment: Removal from exposure. Flush eyes with water. Observe visual disturbances and upper respiratory obstruction

\section{Carbon-dioxide}

CO2 occupational exposure is from a manufacture of fizzy drinks, manufacture of fizzing mixture, mines, in breweries, mineral water factories, coke oven, blast furnaces, and agricultural soils. CO2 is converted to liquefied form and used as fire extinguisher.Carbon dioxide poisoning is also known as Hypercapnia and respiratory acidosis. Carbon dioxide comprise only 385 parts per million our atmosphere, but it can accumulate in the blood to toxic levels. Hypercapnia or Hypercapnia (from the Greek hyper = "above" and kapnos- "Smoke") also known as hypercarbia, is condition where there is too much carbon dioxide (CO2) in the blood. Carbon dioxide is a gaseous product of the body's metabolism and is normally expelled through the lungs, Hypercapnia is generally caused by hypoventilation, lung disease, diminished consciousness. It may also be caused exposure to environment containing abnormally high concentrations of carbon dioxide casually due to volcanic or geothermal cases or by re-breathing exhaled CO2 [8].

Treatment: Removal from exposure. Give oxygen, Supplement 02 to maintain $\mathrm{PO} 2$ of approx. $70-80 \mathrm{~mm} \mathrm{Hg}$ impaired normal oxygenation due to pulmonary injury. Treat the underlying cause if one exists Administer continuous positive airway pressure and provide mechanical ventilation if the patient's breathing is compromised [5].

\section{Methane gas (CH4) (Marsh gas, fire dump)}

Methane is also asphyxiants. Colourless gas, highly flammable. Methane is the major component of a natural gas, about $97 \%$ by volume, at room temperature and standard pressure, methane is colourless, odourless gas the smell characteristic of natural gas is an artificial safety measure caused by the addition of an odorant. As a gas it is flammable only over a narrow range of concentration $5-15 \%$ in air. Methane hazards leads to death from Asphyxiation, death from explosion $[9,13]$.

Treatment: Removal from exposure. Give oxygen. Treat the underline cause like burns injury etc.

\section{Safety Guide for Men Working in Sewers}

Throughout the country there are hundreds of men, in the course of their duties work in manholes or sewers, pumping station or at sewers disposal works. This is works of considerable importance which can be done only by experienced men. How well such sewage and works are designed and executed, their successful operation and freedom from breakdown depends upon the skill of the men who maintain them [14].

\section{Safety is first}

This is also to be observed in maintenance of sewer lines. Safety awareness, i.e. acquiring necessary skill and Knowledge to avoid the hazards around us, among workers and supervisors is a basic requirement. The risks likely to be met in this day to day work no more than those present in general industry. Everybody should know exactly what to do when an accident occurs but prevention is better than cure. One must learn how to avoid accidents. If one is in doubt about any aspect of accident prevention procedure then one must ask the man in charge of his gang or group [15].

In no circumstances should one enter a manhole, sewer, sump or any underground chamber until the necessary safety precautions have been taken, else one may place himself in danger and may hinder the rescue of other. Even if there is an emergency \& Lives are at stake, do not Neglect safety procedure [16].

\section{Statutory provisions for safety}

There are laid down guidelines for safety measures to be adopted by each department in regard to workmen deputed for desilting /cleaning of sewers under section 36 of the Factories Act, 1948. There is also a BIS code of practice for safety precautions to be taken when entering a sewerage system.

\section{Safety equipment}

The various Safety equipments that are normally required in sewer maintenance work are gas masks, oxygen breathing apparatus, portable lighting equipment, no sparking tools, portable air blowers, Safety belts, inhalators, divers suit, bump helmets, gloves, lead acetate paper, barrier cream, head lamp, first aid kits, 
gas detector lamps etc. The use of the particular safety equipment is equipment is governed by the detection of various gases and Oxygen deficiency. Knowledge of the type of gases in the atmosphere and of the working location becomes essential for the selection of the right type of safety equipment. Equipment and simple tests for detection of various gases and Oxygen deficiency are furnished [17].

General purpose gas masks are used for respiratory protection from low and moderately high concentrations of all types of toxic gases and vapors present in the atmosphere in which there is sufficient Oxygen to support life. Masks afford necessary respiratory protection under many circumstances but it is most important to know the limitations of the various types available and to be familiar with their use. Even when masks are used properly, other precautions such as never using open flames or creating sparks in the presence of inflammable gases must be taken .The general purpose gas masks affords protection against organic vapors, acid gases, carbon monoxide up to 2 percent concentration toxic dusts, fumes and smoke. Persons using gas masks should practice regularly with them in order to become proficient in putting them on quickly and breathing through them [18]. Gas masks cannot be used in Oxygen deficient atmospheres, in non ventilated location or areas where large concentration of poisonous gases exist

\section{Breathing apparatus}

This is designed for respiratory protection from atmosphere that contains very high concentrations of toxic gases and vapors or that are deficient in Oxygen. It fully protects a worker against all gases, vapors, dusts, fumes, smokes and oxygen deficiencies and can be safely used in petroleum vapors and is the most dependable device for work in atmospheres normally encountered in sewerage works [19].

\section{Air house respirator}

This is used where a source of fresh air is available within a distance of $50 \mathrm{~m}$ from the working location it is essential that the supply of air is obtained from an uncontaminated source. It consists of a mask which is a tight fitting face piece attached to a large diameter flexible hose, breathing tubes and a harness. Fresh air is blown to the mask through either a power operated or a hand operated blower. An inhalation check valve in the breathing tube assembly and exhalation valve in the face piece permit air flow only in one direction, from the source to the mask. When the blower is in operation. Exhaled air is released into the surrounding atmosphere through the exhalation valve. The valve arrangement permits the wearer to breathe directly through the hose in the event of blower failure $[10,20]$. The maximum length of hose will be about $50 \mathrm{~m}$. The hose being of large diameter permits breathing without excessive resistance in the event of blower failure. A special pressure release value on the blower permits regulation of air delivery and a fresh air bypass valve function automatically in the event of blower failure permitting the wearer to breathe directly through the hose. When a hand operated blower is used the operator will be available to attend to any emergent situation also. This apparatus does not depend on chemical and may be used over extended periods at low costs. Purified air is used where a source of fresh air is not available within $50 \mathrm{~m}$ to permit the use of an air hose respirator or in situations where an air hose would encumber the worker [21].

\section{Portable lighting equipment}

The equipment normally used is portable electronic hand lamps of permissible types. Electric cap lamps and explosion proof flash light.

\section{Non sparking tools}

These are made of an alloy (containing at least 80 percent of copper) that will not spark when struck against other object and metals and yet retains the necessary strength and resistance to wear.

\section{Portable air blowers}

Forced ventilation of manholes pits and tanks can be provided by portable air blowers. Special precautions should be taken to ensure that the blowers do not serve as a source of ignition for inflammable gases. Such precautions shall include placing of the blower upwind from the manhole or at right angles to the wind direction and at least $2 \mathrm{~m}$ away from the opening. The use of such equipment requires a consideration of the depth of the manhole. Size of enclosure and the number of openings to uncontaminated atmosphere. Trailer-mounted blower having a capacity of $210 \mathrm{~m} 3$ / min can ventilate easily many meters of medium sized sewers.

\section{Safety belt}

This consists of a body belt with a buckle and shoulder harness. The life line is of high grade spliced manila rope, nylon rope or a steel cable anchored with rings on each side of the belt and provided with safety straps for anchoring or securing to a stable support The life line should be about $15 \mathrm{~m}$ in length and the overall assembly should be capable of withstanding a tensile load of $2000 \mathrm{kgs}$. The safety belt and life line should be tested by lifting the wearer clear of ground before each day's use.

\section{Inhalators}

Approved inhalants employing a mixture of Oxygen and Carbon Dioxide are used for resuscitating victims of gas collapse, drowning or electric shock. Artificial respiration should be started at once on the patient and an inhalator face piece attached to the victims mouth as soon as the equipment can be made ready. The Carbon Dioxide used in small percentages stimulates deep breathing so that more Oxygen may be dialled. Pure Oxygen should be used only when irritant gases such as Hydrogen sulphide or Chlorine have caused the victim's collapse.

\section{Diver's suit}

Good quality diver suit should be provided to the diver whose services are very necessary while plugging the sewer line or removal of some hard blockage due to stone etc. at the mouth of the pile in the manhole. Depending upon the site condition, suit should 
have provision to connect an air line with compressor or Oxygen cylinder.

\section{Selection of sewer workers, Training and Prerequisite}

Only workers, who are above 18 years of age, physically fit for their task, aware of the possible hazards and alert for action should an emergency arise, shall be employed. The selection of prospective employees for the sewerage and sewage disposal function should take into account the duties they will be expected to perform those duties may be divided into two categories.

a. Duties not requiring entry into confined space

b. Duties requiring entry into confined spaces.

\section{Safety Tips for Working in and Around Sewage}

The importance of practicing safety when working on sewer projects in and around manholes can never be emphasized enough. Keep this information in mind

\section{Warning Signs}

Appropriate warning signs and fencing should always be used around the manhole. This is primarily to notify passersby of the inherent risks of sewer work. Curious people may still attempt to peek at the side of the fence or to get closer to see what's happening. This is why warning signs are important but alone are sometimes not enough to reduce the risk of injuries or problems. There should also be a worker appointed to be outside of the manhole while the work is being completed in case someone inside needs assistance as well as to warn passersby.

\section{Use Appropriate PPE to Avoid Exposure to Dangerous Contaminants and Consider Other Measures}

Individual health and safety regulations should always be reviewed by those coming into contact with sewage. Workers can be exposed to a number of different airborne and waterborne illnesses and other problems. Being sure to use the right equipment and following general best practices is the most appropriate protection. In addition, although there are currently no official suggestions regarding vaccinations for those who are in regular contact with sewage, many employers do provide voluntary vaccinations and an employee can talk directly with their physician about what makes the most sense for them.

\section{Types of Disease Affecting Sewer Workers}

There are four primary types of disease-causing organisms that can affect humans and are found in sewage-bacteria, protozoa, viruses and parasitic worms. PPE can help ensure that these contaminants are kept off of the human body and keep the worker free from scrapes, cuts, scratches and other bodily harm. Employers should be mindful about supplying the proper PPE, as well as enforcing the use of it. Be careful not to cross-contaminate any clean areas when handling and disposing of sewer material. Standard hygiene practices should be given to all sewer workers by a qualified health and safety professional to cover the policies, procedures and risks. These should be managed on a periodic basis.
Gloves are some of the most common safety equipment that can be used to form a barrier between the skin and surfaces. Employees should also be warned about touching their nose, eyes, mouth, face or any open cuts or sores while working.Employees should be told about the dangers of eating in an area near sewage. Designated areas should be established away from the job site. Excess wastewater and debris should always be removed from the foot gear of a sewer worker prior to coming back inside.

\section{First-Aid Kit}

A first-aid kit should always be maintained by the employer with appropriate bandages and the ability to gently flush out eyes if any debris or wastewater comes into contact with a worker's eyes.

\section{Other Protective Equipment}

One important piece of safety gear is a ventilation blower that can help to supply fresh air to the manhole to ensure that the air inside stays safe for workers. Any generators that could be releasing toxic fumes near the area should be removed from the work site as soon as possible. In addition to these considerations, general safety equipment should be properly maintained and inspected by the employer and a sufficient number of people should always be located outside the manhole to be able to respond quickly in the event of an accident. Some of the most common equipment used to respond to emergency situations and to promote overall safety is safety harnesses, rescue ropes, an approved breathing apparatus, protective clothing and safety helmets. These pieces should always be evaluated carefully by the safety inspector before each job. When the proper training meets the right safety equipment, those managing and working in a sewer area have a decreased risk of dealing with accidents, injuries, and personal injury lawsuits. Every time that sewer work is being completed, the same safety checks should be completed to ensure minimal chance of severe accidents and harm done to those in and around the area.

\section{Conclusion}

Nearly a century after Mahatma Gandhi first called for the abolition of manual scavenging, the degrading practice continues. Between 2002 and 2003, the Indian Ministry for Social Justice and Empowerment admitted to the existence of 676,000 scavengers [22]. However, these figures may have been underestimated because scavenging is illegal. According to one survey by Bezwada Wilson of the SafaiKarmachari Association, an estimated 12 lakh (1.2 million) scavengers are present in the country [23]. According to Sulabh [22], four to five million people were working as scavengers in 2005 and were often employed by the local civil bodies to clean excrement in public places [22]. This situation persists despite the fact that the Employment of Manual Scavengers and Construction of Dry Latrines (Prohibition) Act, 1993, is in enforcement, which provides for the prohibition of the employment of manual scavengers as well as construction or continuance of dry latrines and for the regulation of construction and maintenance of waterseal latrines for assuring the dignity of the individual, as enshrined in the Preamble to the Constitution. 
The working conditions of the sanitary workers have remained virtually unchanged for over a century. Using only a stick broom and a small tin plate, the sanitary workers clear feces from public and private latrines onto baskets or other containers, which they then carry on their heads to dumping grounds and disposal sites. A few, however, are provided with wheelbarrows or carts by the municipal authorities [2].

Apart from the social atrocities that these workers face, they are also exposed to certain health problems by virtue of their occupation. These health hazards include exposure to harmful gases, cardiovascular degeneration, musculoskeletal disorders, infections, skin problems and respiratory system problems.

\section{References}

1. ILO (1970) Encyclopaedia of occupational health and safety International labourorganization, Geneva, Switzerland, pp. 1251-1253.

2. Ambekar AN, Bharadwaj RS, Joshi SA, Kagal AS, Bal AM (2004) Sero surveillance of leptospirosis among sewer workers in Pune. Indian J Public Health 48(1): 27-29.

3. Watt MM, Watt SJ, Seaton A (1997) Episode of toxic gas exposure in sewer workers. Occup Environ Med 54(4): 277-280.

4. Friedrich M, Cermak T, Heiller I (2000) Spinal troubles in sewage workers: Epidemiological data and work disability due to low back pain. Int Arch Occup Environ Health 73(4): 245-254.

5. De Serres G, Levesque B, Higgins R, Major M, Laliberte D, et al. (1995) Need for vaccination of sewer workers against leptospirosis and hepatitis A. Occup Environ Med 52(8): 505-507.

6. Glas C, Hotz P, Steffen R (2001) Hepatitis A in workers exposed to sewage: A systematic review. Occup Environ Med. 58(12):762-768.

7. Vaidya SR, Tilekar BN, Walimbe AM, Arankalle VA (2003) Increased risk of hepatitis E in sewage workers from India. J Occup Environ Med45(11): $1167-1170$

8. Arvanitidou M, Constantinidis TC, Doutsos J, Mandraveli K, Katsouyannopoulos V (1998) Occupational hepatitis B virus infection in sewage workers. Med Lav89(5): 437-444.

9. Friis L, Engstrand L, Edling C (1996) Prevalence of Helicobacter pylori infection among sewage workers. Scand J Work Environ Health22(5): 364-368.
10. Zuskin E, Mustajbegovic J, Lukenda-Simovic D, Ivankovic D (1990) Respiratory symptoms and ventilatory capacity of sewage canal workers. LijecVjesn112(11-12): 353-357.

11. Richardson DB (1995) Respiratory effects of chronic hydrogen sulfide exposure. Am J Ind Med28(1): 99-108.

12. Brautbar N, Navizadeh N (1999) Sewer workers: Occupational risk for hepatitis C-report of two cases and review of literature. Arch Environ Health54(4): 328-330.

13. Nethercott JR (1981) Airborne irritant contact dermatitis due to sewage sludge. J Occup Med 23(11): 771-774.

14. Keeffe EB (2004) Occupational risk for hepatitis A: A literature-based analysis. J Clin Gastroenterol 38(5): 440-448.

15. Brugha R, Heptonstall J, Farrington P, Andren S, Perry K, et al. (1998) Risk of hepatitis A infection in sewage workers. Occup Environ Med 55(8): 567-569.

16. Tooher R, Griffin T, Shute E, Maddern G (2005) Vaccinations for wastehandling workers: A review of the literature. Waste Manag Res 23(1): 79-86

17. Thorn J, Beijer L, Rylander R (2002) Work related symptoms among sewage workers: A nationwide survey in Sweden. Occup Environ Med 59(8): 562-566.

18. Rylander R (1999) Health affects among workers in sewage treatment plants. Occup Environ Med 56(5): 354-357.

19. Levin M, Froom P, Trajber I, Lahat N, Askenazi S, et al. (2000) Risk of hepatitis A virus infection among sewage workers in Israel. Arch Environ Health 55(1): 7-10.

20. Zuskin E, Mustajbegovic J, Schachter EN (1993) Respiratory function in sewage workers. Am J Ind Med 23(5): 751-761.

21. Nethercott JR, Holness DL (1988) Health status of a group of sewage treatment workers in Toronto, Canada. Am Ind Hyg Assoc J 49: 346-350.

22. Kothandaraman P, Vishwanathan V (2007) Sulabh international: A movement to liberate scavengers by implementing a low-cost, safe sanitation system, USA.

23. Zaidi A (2006) India's shame. Frontline, pp. 9-22.
Creative Commons Attribution 4.0

International License

For possible submissions Click Here
Submit Article

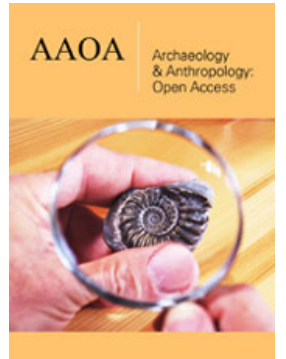

\section{Archaeology \& Anthropology: Open Access}

\section{Benefits of Publishing with us}

- High-level peer review and editorial services

- Freely accessible online immediately upon publication

- Authors retain the copyright to their work

- Licensing it under a Creative Commons license

- Visibility through different online platforms 